\title{
Dissolution Kinetics: Catalysis by Strong Acids
}

\author{
W. E. KLINE ${ }^{1}$ AND H. S. FOGLER \\ Department of Chemical Engineering, The University of Michigan, Ann Arbor, Michigan 48109
}

Received April 11, 1980; accepted October 14, 1980

\begin{abstract}
The dissolution of silicate minerals in mixtures of hydrofluoric acid and strong acids such as $\mathrm{HCl}$ is catalyzed by $\mathrm{H}^{+}$ions adsorbed at the mineral surface. Studies of the catalyzed dissolution of kaolinite, quartz, potassium feldspar, and sodium montmorillonite have shown that the rates of dissolution can be increased by as much as $900 \%$. The dissolution process can be modeled as simultaneous catalyzed and uncatalyzed reactions, where the surface concentration of $\mathrm{H}^{+}$ions is determined by a Langmuir adsorption isotherm. The degree of catalysis is a strong function of the nature of the silicate surface, a fact which has application in the area of selective dissolution within mixed mineral systems.
\end{abstract}

\section{INTRODUCTION}

It is well known that the attack of silicate minerals by strong acids such as $\mathrm{HCl}$ is negligible compared to the rate of dissolution in hydrofluoric acid. Even so, these dissolution reactions are almost never carried out in solutions containing only hydrofluoric acid, but in mixtures containing both hydrofluoric and strong acids. In the acid treatment of sandstone petroleum reservoirs, for example, the injected fluid typically contains $3 \% \mathrm{HF}$ and $12 \% \mathrm{HCl}$. The presence of strong acids is important for three reasons. First, a low $\mathrm{pH}$ is necessary in order to prevent precipitation of the dissolution products in the form of calcium, sodium, and potassium salts. Second, the $\mathrm{H}_{3} \mathrm{O}^{+}$in solution shifts the equilibrium of the product distribution toward silicon and aluminum complexes coordinated by fewer fluorine atoms, thus reducing the consumption of HF (1). Third, it has been observed that the presence of strong acids actually increases the rates at which the silicates are dissolved.

The increased rates of silicate dissolution in the presence of strong acids do not result from greater concentrations of the fluoride

\footnotetext{
${ }^{1}$ Present Address: Exxon Production Research Houston, TX.
}

species attacking the mineral lattice. At $\mathrm{pH}$ values less than 1 , virtually all of the fluorine present in solutions of hydrofluoric acid is in the form of molecular HF. Consequently, further increases in the concentration of $\mathrm{H}_{3} \mathrm{O}^{+}$do not appreciably change the concentration of the attacking species, although the rates of dissolution can be increased substantially. Moreover, this laboratory has shown (2) that any effects of the fluoride and bifluoride anions on the rates of silicate dissolution are negligible.

It can be further concluded that the effect of strong acids is not related to the consumption of $\mathrm{H}^{+}$. Hekim and Fogler (1) described the stoichiometry and equilibria of silicate dissolution in mixtures of $\mathrm{HF}$ and $\mathrm{HCl}$, and determined that virtually no $\mathrm{H}^{+}$is consumed during the course of reaction. Indeed, it was shown that in some cases $\mathrm{H}^{+}$ can even be produced. Since the enhanced rates of silicate dissolution when strong acids are present cannot be attributed to changes in the identity or concentration of the species consumed, the exciting conclusion is that the observed increases result from a catalytic process at the solid-liquid interface.

Despite the fundamental significance of a catalyzed solid-liquid heterogeneous reac- 


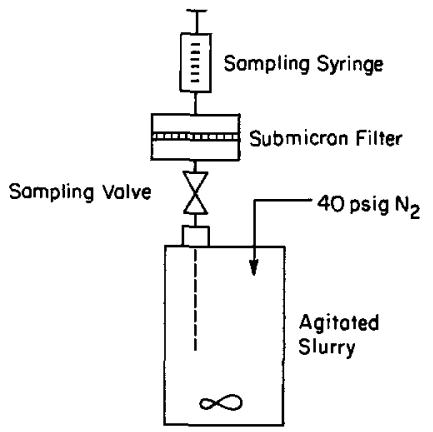

FIG. 1. Slurry reactor.

tion, this effect has been considered in detail by only one previous investigation. Fogler et al. (3) used a rotating disk to study the dissolution of sodium and potassium feldspars in mixtures of $\mathrm{HF}$ and $\mathrm{HCl}$. A rate law relating the kinetics of dissolution to the concentrations of $\mathrm{HF}$ and $\mathrm{HCl}$ of the form

$$
-r=k(\mathrm{HF})\left(1+K(\mathrm{HCl})^{a}\right)
$$

was obtained. It was concluded that the overall dissolution results from parallel catalyzed and uncatalyzed reactions, and that the catalyzed reaction consists of $\mathrm{HF}$ attack at sites occupied by adsorbed $\mathrm{H}^{+}$ ions. The adsorption of the catalyzing hydrogen ions was described by a Freundlich adsorption isotherm:

$$
C_{\mathrm{H}^{+} \text {surface }}=K^{\prime}\left(C_{\mathrm{H}^{+} \text {bulk }}\right)^{a} .
$$

In this paper, the catalysis by strong acids is further studied by experiments with potassium feldspar, quartz, kaolinite clay, and sodium montmorillonite clay. The results confirm the conclusions of Fogler et al. (3), both that the overall dissolution is comprised of parallel catalyzed and uncatalyzed reactions and that the catalysis results from the adsorption of $\mathrm{H}^{+}$at the dissolving surfaces. In addition, an important discovery has been made that the catalysis of each silicate is bounded by a characteristic maximum, which is a strong function of the nature of the surface. This finding has important application in the area of selective dissolution within mixed mineral systems.

\section{EXPERIMENTAL}

Rates of dissolution were measured by initial rate experiments carried out in a batch, slurry reactor, shown in Fig. 1. The use of a slurry reactor enables reaction rates to be measured for naturally fine-grained minerals such as clays. The reactor is a $150-$ $\mathrm{cm}^{3}$ Hastelloy vessel, with agitation provided by a magnetic stirring bar. Temperature is maintained by a surrounding water bath. The dissolving slurry is placed under nitrogen pressure, allowing samples to be withdrawn at short time intervals through submicrometer filters. Filtration of the suspended particles stops the dissolution reaction, so the filtrate samples are representative of dissolved mineral as a function of time. The progress of the reaction is followed by analyzing the filtrate samples for dissolved lattice components by atomic absorption spectroscopy. It has been shown (2) that when silicates are dissolved by hydrofluoric acid the rates of dissolution with respect to aluminum and silicon are proportional to their concentrations within the lattice.

The slurry reactor also allows the dissolution process to be studied within the kinetic regime. For the small particles used in these experiments (less than $5 \mu \mathrm{m}$ for clays, less than $20 \mu \mathrm{m}$ for feldspar and quartz) it can be shown that the rates of mass transfer to the surfaces are orders of magnitude larger than the observed rates of dissolution $(4,5)$.

The quartz particles used in these experiments were obtained by pulverizing waterclear hexagonal crystals from Mount Ida, Arkansas. Atomic absorption analysis of the totally dissolved quartz showed the chemical composition to be pure $\mathrm{SiO}_{2}$. The potassium feldspar (near Keystone, S. D.) was identified by $\mathrm{X}$-ray diffraction as $80 \%$ microcline and $20 \%$ plagioclase (3). Atomic absorption analysis of the totally dissolved mineral gave the following elemental composition:

$$
\left(\mathrm{K}_{0.76} \mathrm{Na}_{0.18} \mathrm{Si}_{0.94}\right)(\mathrm{CaAl})_{0.06} \mathrm{AlSi}_{2} \mathrm{O}_{8} .
$$




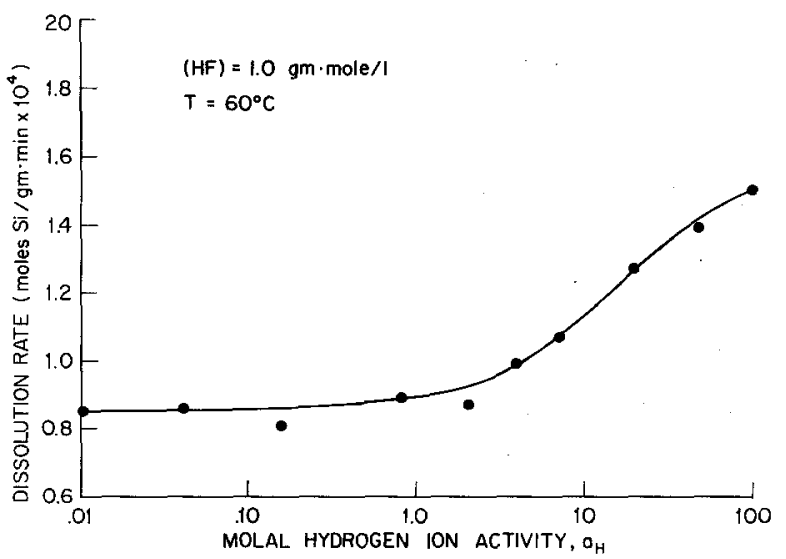

FIG. 2. Initial rates of quartz dissolution as a function of the hydrogen ion activity.

The kaolinite particles consisted of the 3- to 5- $\mu \mathrm{m}$ fraction of Mesa Alta, New Mexico, reference material. Minor impurities of colloidal silica were present. The sodium montmorillonite was a Wyoming bentonite having the following chemical analysis as determined by atomic absorption:

$$
\mathrm{Na}_{0.7} \mathrm{Al}_{1.6} \mathrm{Mg}_{0.2} \mathrm{Fe}_{0.2} \mathrm{Si}_{3.7} \mathrm{Al}_{0.3} \mathrm{O}_{10}(\mathrm{OH})_{2} \text {. }
$$

All of the solutions employed in this work were made up using Baker reagent-grade acids and double-distilled water. The hydrogen ion activities were calculated using tabulated (6) mean molal activity coefficients. The activity coefficient for the undissociated HF molecules was assumed to be one. This simplification is justified by previous experiments with kaolinite which showed a strict first-order functionality over an HF concentration range of 0.1 to 2.5 g-moles/liter.

The study of any chemical reaction in solutions of electrolytes must consider the ionic activities. At high concentrations of strong acids the ionic activity coefficients are substantially greater than one, and the assumption of equating activities and ionic concentrations is not valid. The hydrogen ion activities $a_{\mathrm{H}}$ were calculated using mean molal activity coefficients tabulated for strong acids (6).

\section{DESCRIPTION OF CATALYSIS BY STRONG ACIDS}

The degree of acid catalysis, $D_{\mathrm{AC}}$, is defined as the fraction by which the overall rate of dissolution, $-r$, is greater than the uncatalyzed reference rate, $-r_{0}$ :

$$
D_{\mathrm{AC}}=\frac{r}{r_{0}}-1
$$

Since HF undergoes dissociation, some catalyzing hydrogen ions are always present in solution. The $\mathrm{pH}$ of a solution in $1 \mathrm{~N}$ hydrofluoric acid, for example, is 1.3 at $25^{\circ} \mathrm{C}$. The uncatalyzed rates can be determined only by extrapolation. These rates were obtained from a series of experiments

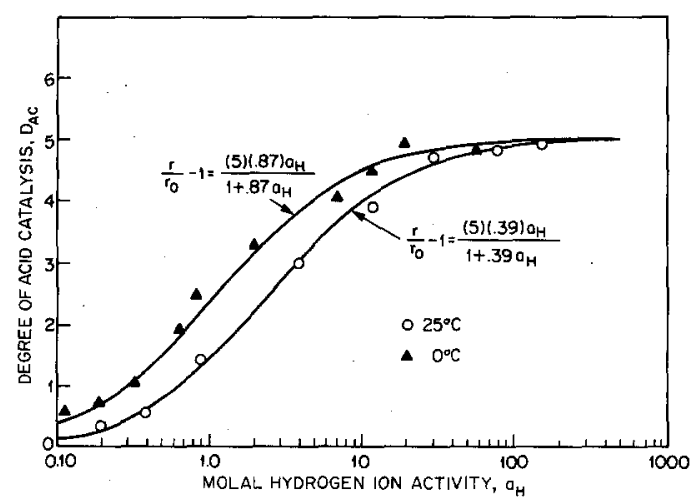

FIG. 3. Acceleration of kaolinite dissolution rates by $\mathrm{HCl}$. 


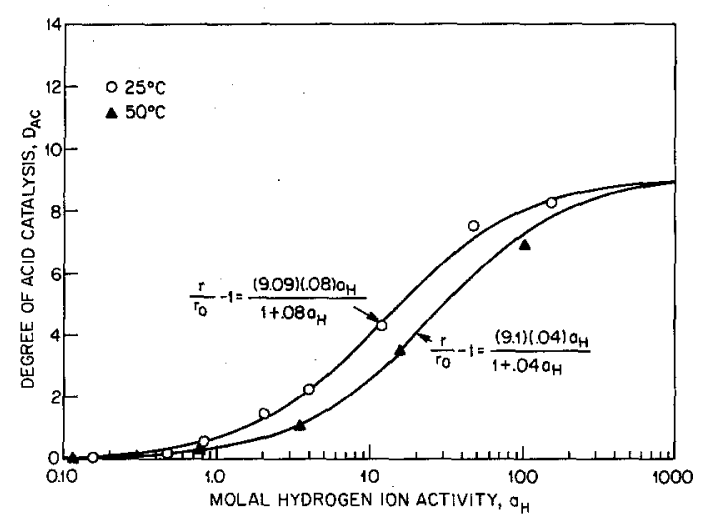

FIG. 4. Acceleration of potassium feldspar dissolution by $\mathrm{HCl}$.

in mixtures of $\mathrm{HF}$ and $\mathrm{HCl}$ made up so that the activity of the undissociated HF remained constant as the hydrogen ion activity was decreased. The uncatalyzed rate at a given concentration of HF was then determined by extrapolating the experimental values of $-r$ back to zero $\mathrm{H}^{+}$activity. In Fig. 2, such a plot is shown on semilog coordinates in order to expand the low end of the activity axis. It can be seen that the rate of dissolution approaches a constant value as the activity of the hydrogen ion becomes small, and it is this asymptote that is defined as $-r_{0}$. The fact that the rate of reaction does not go to zero when the hydrogen ion activity is very small constitutes evidence that the catalyzed reaction is simultaneous with the uncatalyzed attack by the HF molecules.

The degree of catalysis for the dissolution of kaolinite, potassium feldspar, quartz, and sodium montmorillonite is shown as a function of the activity of the hydrogen ion and temperature in Fig. 3 through 6 . Note that the acceleration of the rates of dissolution is not limited to incidental increases of only a few percent: Rather, the amounts of increase can be significantly larger than even the original uncatalyzed rate $-r_{0}$. The dissolution of potassium feldspar, for example, can be catalyzed by as much as $900 \%$.

One observes from Fig. 7 that the catalytic action of strong acids can be solely attributed to the presence of the $\mathbf{H}^{+}$ion, rather than the associated anions. The catalytic effects of a number of strong acids on the dissolution of kaolinite are virtually the same. This independence of the anion was observed for all of the silicates studied. The conclusion that the hydrogen ion is the catalytic agent is consistent with the fact that protons are chemically adsorbed by hydroxyl groups on the silicate surfaces (7).

Several experiments were performed in order to investigate the effect of agitating the silicate particles in $\mathrm{HCl}$ prior to the addition of the hydrofluoric acid. In all cases the measured rates of dissolution were identical to those obtained when the hydrofluoric acid and the hydrochloric acid were introduced simultaneously. It can be concluded, therefore, that the equilibrium surface concentration of $\mathrm{H}^{+}$is established very rapidly compared to the rate of dissolution.

The possibility that the catalyzing hydrogen ions have diffused throughout the silicate lattice, as opposed to only the particle surface, was investigated by initial-rate experiments with kaolinite particles which were suspended overnight in $10 \mathrm{~N} \mathrm{HCl}$, collected by filtration, and then dissolved in solutions containing only hydrofluoric acid. The rates of dissolution were the same as those measured for particles which had not been previously exposed to any acid. If the catalyz-

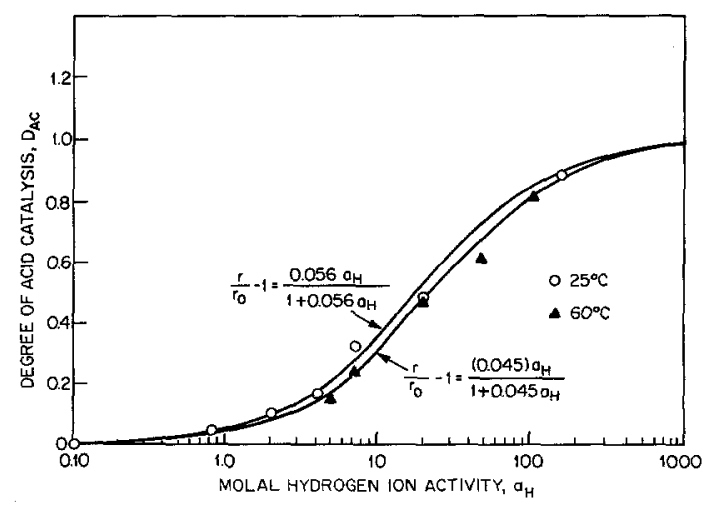

FIG. 5. Acceleration of quartz dissolution rates by $\mathrm{HCl}$. 
ing hydrogen ions are adsorbed throughout the silicate structure, it is likely that an appreciable concentration of protons remains in the lattice when the kaolinite particles are removed from the $10 \mathrm{~N} \mathrm{HCl}$ and transferred to the HF solution, and that these protons would catalyze the initial rates of dissolution even when the bulk concentration of $\mathrm{H}^{+}$is low. The fact that no increases in the rates of reaction were observed indicates that the catalyzed reaction takes place at the silicate surface.

Figure 7 also shows that the fractional catalysis of $\mathrm{H}^{+}$is independent of the concentration of HF. Consequently, the degree of acid catalysis, $D_{\mathrm{AC}}$, is not a function of the uncatalyzed rate, $-r_{0}$. This independence is further illustrated by kinetic rate laws representing the dissolution of sodium montmorillonite in mixtures of $\mathrm{HF}$ and $\mathrm{HCl}$, as presented in Table $\mathrm{I}$. The equilibrium constant for HF adsorption (2), $K_{\mathrm{A}}$, is not appreciably affected by the concentration of $\mathrm{HCl}$, implying that the catalytic action of the adsorbed $\mathrm{H}^{+}$ions is not simply to enhance the adsorption of the attacking HF molecules. Furthermore, analysis of the rate laws describing each of the possible modes of adsorption followed by surface reaction shows that only a rate law based on the assumption of independent adsorption at dif-

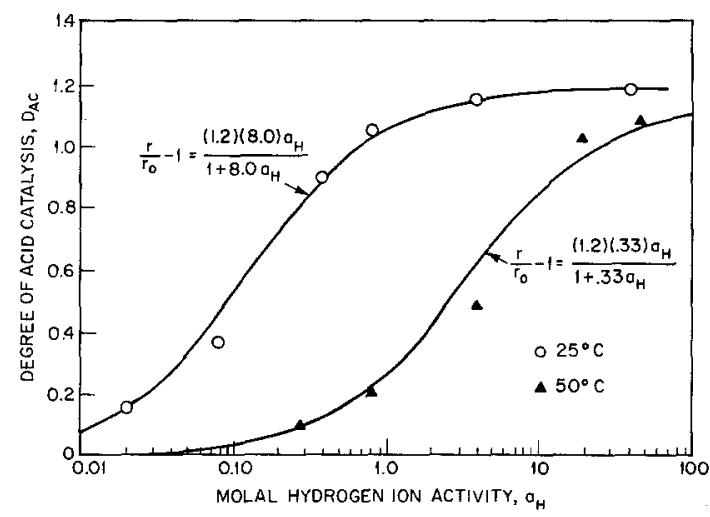

FIG. 6. Acceleration of sodium montmorillonite dissolution rates by $\mathrm{HCl}$.

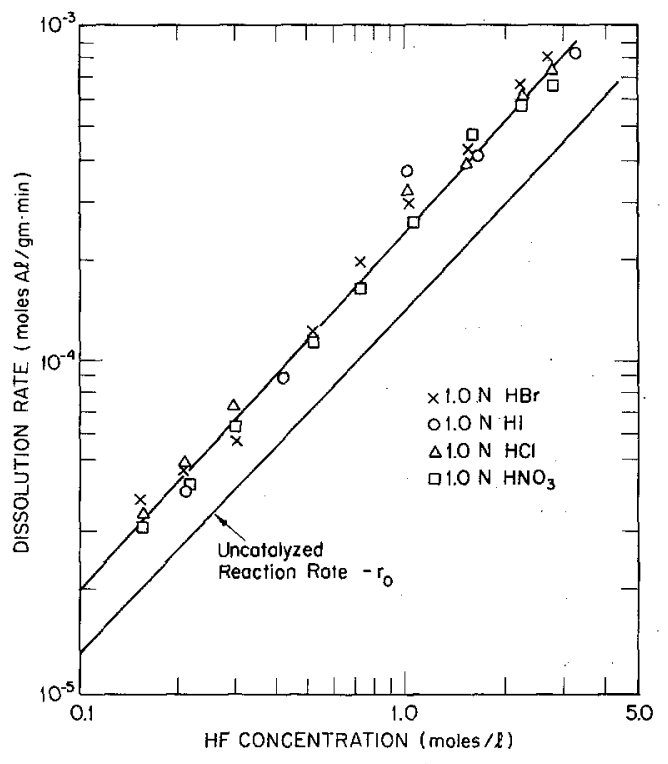

FIG. 7. Catalysis of kaolinite dissolution by strong acids.

ferent sites predicts catalysis that is independent of the concentration of HF. It is concluded that the $\mathrm{H}^{+}$ions and the HF molecules do not compete for the same adsorption sites.

Another important result of this investigation is that the degree of catalysis is not an unbounded function of the bulk concentration of $\mathrm{H}^{+}$. Rather, the catalysis of the dissolution of any given silicate is limited by a specific maximum value. In the context of a surface reaction, the asymptotic nature of Figs. 3 through 6 constitutes further evidence of equilibrium between the $\mathrm{H}^{+}$ions in the bulk and unoccupied catalysis sites, where the asymptote represents the limit of total surface coverage. These maxima moreover, vary widely among the minerals studied. Consequently it is possible to effect substantial changes in the relative rates at which two or more minerals dissolve. This result suggests the possibility of applications in solution mining, where the goal is to selectively leach valuable minerals from a surrounding matrix. It is feasible that large increases in yields may be obtained 


\section{TABLE I}

Rate Laws for the Dissolution of Sodium Montmorillonite in Mixtures of Hydrofluoric and Hydrochloric Acids

\begin{tabular}{cc}
\hline & $-r=\frac{k K_{\mathrm{A}} a_{\mathrm{HF}}}{1+K_{\mathrm{A}} a_{\mathrm{HF}}}$ \\
\hline $\mathrm{HCl}(M)$ & $-r\left(\frac{\mathrm{moles} \mathrm{Al}}{\mathrm{g} \cdot \mathrm{min}}\right)\left(25^{\circ} \mathrm{C}\right)$ \\
\hline 0.0 & $\frac{2.6 \times 10^{-4} a_{\mathrm{HF}}}{1+0.39 a_{\mathrm{HF}}}$ \\
0.1 & $\frac{3.0 \times 10^{-4} a_{\mathrm{HF}}}{1+0.31 a_{\mathrm{HF}}}$ \\
1.0 & $\frac{4.6 \times 10^{-4} a_{\mathrm{HF}}}{1+0.44 a_{\mathrm{HF}}}$ \\
3.0 & $\frac{7.4 \times 10^{-4} a_{\mathrm{HF}}}{1+0.43 a_{\mathrm{HF}}}$ \\
\hline
\end{tabular}

by appropriate design of the composition of the injected fluids.

\section{DEVELOPMENT OF A KINETIC MODEL}

The experimental evidence indicates that the overall dissolution consists of parallel catalyzed and uncatalyzed reactions. The nature of the uncatalyzed reaction and the characteristic rate laws have been discussed previously (2). The adsorption of HF followed by a surface reaction is represented by equations of the form

$$
\begin{aligned}
\mathrm{HF}+\mathrm{S}^{\prime} & \leftrightarrows \mathrm{HF} \cdot \mathrm{S}^{\prime}, \\
\mathrm{HF} \cdot \mathrm{S}^{\prime} & \rightarrow \text { Products, } \\
-r_{\text {uncatalyzed }} & =k^{\prime} C_{\mathrm{HF} \cdot \mathrm{S}^{\prime}} \\
& =\frac{k^{\prime} K_{\mathrm{A}}\left(a_{\mathrm{HF}}\right) C_{\mathrm{T}^{\prime}}}{1+K_{\mathrm{A}}\left(a_{\mathrm{HF}}\right)},
\end{aligned}
$$

where $\left(a_{\mathrm{HF}}\right)$ is the bulk activity of undissociated $\mathrm{HF}, C_{\mathrm{HF} \cdot \mathrm{S}^{\prime}}$ is the concentration of sites occupied by adsorbed $\mathrm{HF}, C_{\mathrm{T}^{\prime}}$ is the total concentration of sites that can be occupied, $K_{\mathrm{A}}$ is the equilibrium adsorption constant, and $k^{\prime}$ is the specific rate constant for the uncatalyzed reaction. Equation [4] is a familiar Langmuir-Hinshelwood-type rate law used to describe heterogeneous reactions.

The catalyzed reaction, on the other hand, is a function of the surface concentration of both $\mathrm{HF}$ and $\mathrm{H}^{+}$. The surface equilibrium, however, is complicated by the fact that the hydroxyl sites at which the hydrogen ions are adsorbed can assume a positive, negative, or neutral charge (7),<smiles>[X]C([X])([X])O</smiles>

where $\mathrm{X}$ represents a lattice atom such as aluminum or silicon. Designating the negative, neutral, and positive sites as $\mathrm{S}^{-}, \mathrm{S}$, and $\mathrm{H}^{+} \cdot \mathrm{S}$, respectively, the appropriate equilibrium expressions are

$$
\begin{aligned}
& \mathrm{S}^{-}+\mathrm{H}^{+} \leftrightarrows \mathrm{S}, \\
& \mathrm{S}+\mathrm{H}^{+} \leftrightarrows \mathrm{H}^{+} \cdot \mathrm{S} .
\end{aligned}
$$

The surface concentrations, therefore, are given by

$$
\begin{aligned}
C_{\mathrm{S}} & =\left(K_{1} a_{\mathrm{H}}\right) C_{\mathrm{S}^{-}}, \\
C_{\mathrm{H}^{+} \cdot \mathrm{s}} & =\left(K_{2} a_{\mathrm{H}}\right) C_{\mathrm{S}}=\left(K_{1} a_{\mathrm{H}}\right)\left(K_{2} a_{\mathrm{h}}\right) C_{\mathrm{S}^{-}},
\end{aligned}
$$

where $a_{\mathrm{H}}$ is the activity of the catalyzing hydrogen ion and $K_{1}$ and $K_{2}$ are the equilibrium adsorption constants.

Since

$$
C_{\mathrm{T}}=C_{\mathrm{S}^{-}}+C_{\mathrm{s}}+C_{\mathrm{H}^{+} \cdot \mathrm{s}}
$$

one can write

$$
\begin{aligned}
C_{\mathrm{S}^{-}} & =\frac{C_{\mathrm{T}}}{1+K_{1} a_{\mathrm{H}}\left(1+K_{2} a_{\mathrm{H}}\right)}, \\
C_{\mathrm{S}} & =\frac{K_{1} a_{\mathrm{H}} C_{\mathrm{T}}}{1+K_{1} a_{\mathrm{H}}\left(1+K_{2} a_{\mathrm{H}}\right)}, \\
C_{\mathrm{H}^{+} \cdot \mathrm{S}} & =\frac{\left(K_{1} a_{\mathrm{H}}\right)\left(K_{2} a_{\mathrm{H}}\right) C_{\mathrm{T}}}{1+K_{1} a_{\mathrm{H}}\left(1+K_{2} a_{\mathrm{H}}\right)} .
\end{aligned}
$$

The equilibrium constants $K_{1}$ describe the acidity of the hydroxyl groups associated with the aluminum and silicon lattice atoms. Hence they may be estimated from pub- 
lished $\mathrm{p} K$ data for alumina and silicic acid (8). At $25^{\circ} \mathrm{C}$,

$$
\begin{aligned}
K_{1}(\text { alumina }) & =1.6 \times 10^{11}, \\
K_{1}(\text { silicic acid }) & =5.9 \times 10^{9} .
\end{aligned}
$$

The smallest practical concentration of $\mathrm{H}^{+}$ that can be attained by adding $\mathrm{F}^{-}$salts to the HF solution is $10^{-4} \mathrm{~g}$-moles/liter. (Further addition of salts results in the precipitation of $\mathrm{M}_{3} \mathrm{AlF}_{6}$ and $\mathrm{M}_{2} \mathrm{SiF}_{4}$ complexes, where $\mathrm{M}^{+}$is the salt cation (1).) The value of the product $K_{1} a_{\mathrm{H}}$, therefore, is large over the experimental range of $\mathrm{H}^{+}$concentrations studied, and consequently

$$
1+K_{1} a_{\mathrm{H}}\left(1+K_{2} a_{\mathrm{H}}\right)=K_{1} a_{\mathrm{H}}\left(1+K_{2} a_{\mathrm{H}}\right) .
$$

Hence Eqs. [5] through [7] can be simplified to

$$
\begin{aligned}
C_{\mathrm{S}^{-}} & =\frac{C_{\mathrm{T}}}{K_{1} a_{\mathrm{H}}\left(1+K_{2} a_{\mathrm{H}}\right)}, \\
C_{\mathrm{S}} & =\frac{C_{\mathrm{T}}}{1+K_{2} a_{\mathrm{H}}}, \\
C_{\mathrm{H}^{+} \cdot \mathrm{S}} & =\frac{K_{2} a_{\mathrm{H}} C_{\mathrm{T}}}{1+K_{2} a_{\mathrm{H}}} .
\end{aligned}
$$

The fact that the product $K_{1} a_{\mathrm{H}}$ is large over the experimental range also means that the equilibrium fraction of the total sites consisting of undissociated hydroxyls, $C_{\mathrm{S}^{-}} /$ $C_{\mathrm{T}}$, is very small. Even at the lower limit of $a_{\mathrm{H}}=10^{-4}$

$$
\frac{C_{\mathrm{S}^{-}}}{C_{\mathrm{T}}}<10^{-5} .
$$

Virtually all of the $\mathrm{H}^{+}$adsorbed following the addition of strong acids, therefore, results in the formation of $\mathrm{H}^{+} \cdot \mathrm{S}$ sites, and the catalyzed reaction can be written as

$$
\mathrm{HF} \cdot \mathrm{S}^{\prime}+\mathrm{H}^{+} \cdot \mathrm{S} \rightarrow \text { products. }
$$

Assuming a first-order dependence with respect to both the attacking HF molecules and the catalyzing $\mathrm{H}^{+}$ions, one can now write the following rate law for the catalyzed reaction:

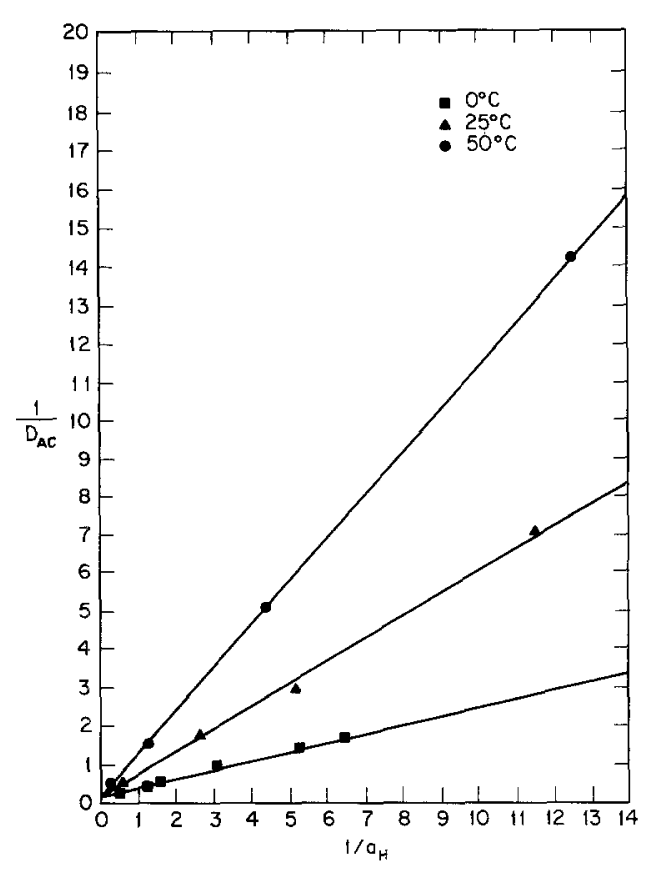

Frg. 8. Linearization of model for the catalyzed dissolution of kaolinite.

or

$$
-r_{\text {catalyzed }}=k C_{\mathrm{HF} \cdot \mathrm{S}} C_{\mathrm{H}^{+} \cdot \mathrm{S}}
$$

$-r_{\text {catalyzed }}$

$$
=\frac{k C_{\mathrm{T}^{\prime}} C_{\mathrm{T}} K_{\mathrm{A}}(\mathrm{HF})}{1+K_{\mathrm{A}}(\mathrm{HF})} \frac{K_{2} a_{\mathrm{H}}}{1+K_{2} a_{\mathrm{H}}}
$$

Combining constants and adding Eqs. [4] and [11] for the uncatalyzed and catalyzed reactions gives an expression for the overall rate of dissolution:

$$
\begin{aligned}
& -r=\frac{k_{0} K_{\mathrm{A}}\left(a_{\mathrm{HF}}\right)}{1+K_{\mathrm{A}}\left(a_{\mathrm{HF}}\right)} \\
& \quad \times\left(1+\frac{k_{1}}{k_{0}} \frac{K_{2} a_{\mathrm{H}}}{1+K_{2} a_{\mathrm{H}}}\right) .
\end{aligned}
$$

One notes that the first term of the righthand side of Eq. [12] is $-r_{0}$, the observed rate of dissolution at very small values of $a_{\mathrm{H}}$. Consequently the fraction by which the dissolution is catalyzed by the presence of strong acids in the bulk solution, $D_{\mathrm{AC}}$, can be written as 
TABLE II

Experimental Values of Catalysis Parameter $P_{\mathrm{C}}$ and the $\mathrm{H}^{+}$Adsorption Constant $K_{2}$

\begin{tabular}{lcccc}
\hline Mineral & $\begin{array}{c}\text { Tempera- } \\
\text { ture } \\
\left({ }^{\circ} \mathrm{C}\right)\end{array}$ & $P_{\mathrm{C}}$ & $K_{2}$ & $\begin{array}{c}\text { Calculated } \\
\Delta H \\
\text { (kcall } \\
\text { g-mole) }\end{array}$ \\
\hline Kaolinite & 0 & 5 & 0.87 & \\
& 25 & 5 & 0.39 & -5.9 \\
& 50 & 5 & 0.18 & \\
Potassium & 25 & 9 & 0.08 & -5.3 \\
feldspar & 50 & 9 & 0.04 & \\
Quartz & 25 & 1 & 0.056 & -1.7 \\
& 60 & 1 & 0.045 & \\
Sodium mont- & 25 & 1.2 & 8.0 & -24.5 \\
morillonite & 50 & 1.2 & 0.33 & \\
\hline
\end{tabular}

$$
\begin{aligned}
D_{\mathrm{AC}} & =\frac{r}{r_{0}}-1=\frac{k_{1}}{k_{0}} \frac{K_{2} a_{\mathrm{H}}}{1+K_{2} a_{\mathrm{H}}} \\
& =P_{\mathrm{C}}\left(\frac{K_{2} a_{\mathrm{H}}}{1+K_{2} a_{\mathrm{H}}}\right) .
\end{aligned}
$$

The parameter $P_{\mathrm{C}}$ is the ratio of the catalyzed specific reaction rate constant, $k_{1}$, to the uncatalyzed constant, $k_{0}$, and is termed the catalysis parameter. The catalysis parameter represents the asymptotic limit of the degree of catalysis at large values of $a_{\mathrm{H}}$, which correspond to saturation of the surface sites. The term $K_{2}$ describes the adsorption to hydrogen ions to form the positive sites.

\section{EVALUATION AND INTERPRETATION OF THE RATE LAW PARAMETERS}

The validity of the Langmuir-Hinshelwood kinetics used in the model can be tested by plotting $1 / D_{\mathrm{AC}}$ as a function of $1 / a_{\mathrm{H}}$ :

$$
\frac{1}{D_{\mathrm{AC}}}=\frac{1}{P_{\mathrm{c}} K_{2}}\left(\frac{1}{a_{\mathrm{H}}}\right)+\frac{1}{P_{\mathrm{c}}}
$$

As shown in Fig. 8, linear relationships were obtained over the entire concentration range and at each temperature. Adsorp- tion and catalysts parameters, $K_{2}$ and $P_{\mathrm{C}}$, respectively, given in Table II were obtained from the slopes and intercepts of these lines. In addition, the degree of catalysis predicted by substituting these parameters back into Eq. [13] is represented by the solid curves in Figs. 3 through 6. It can be seen that the agreement between the predicted catalysis and the measured rate increase is excellent.

One notes from Table II that the catalysis parameter, $P_{\mathrm{C}}=k_{1} / k_{0}$, is independent of temperature. This characteristic is also evident in Figs. 3 through 6, in that each curve for a given mineral is asymptotic to the same maximum. Since the rate constants $k_{0}$ and $k_{1}$ are described (2) by an Arrhenius temperature dependence,

$$
k=A\left(\exp \frac{-E}{R T}\right)
$$

the fact that the ratio $k_{1} / k_{0}$ is not a function of temperature indicates that both rate constants are characterized by the same apparent activation energy, $E$, and that $P_{\mathrm{C}}$ is simply the ratio of the preexponential constants, $A_{1} / A_{0}$. This result cannot be explained by postulating that the activation energies are small for both reactions. For the uncatalyzed dissolution of kaolinite, for example, an activation energy of $13 \mathrm{kcal} /$ g-mole was obtained from a plot of $\ln k_{0}$ as a function of $1 / T$ (2).

The observation that the rate constants $k_{0}$ and $k_{1}$ have the same activation energy suggests that the uncatalyzed and catalyzed reactions proceed through similar intermediates. Since hydrogen ions clearly play a role in the catalyzed reaction, a condition of similar intermediates would require that the uncatalyzed attack by HF molecules also involve a protonation step. The nature of the uncatalyzed intermediate is suggested by a mechanism discussed by Iler (7) and by Strelko (9). Both investigators concluded that the highly nucleophilic nature of fluorine 
increases the coordination of the surface silicon, aluminum, and magnesium atoms, thus weakening the lattice bonds. When HF molecules are adsorbed at the silicate surface, the surface bonds are further weak- ened by the association of the HF protons with the adjacent lattice oxygens. Consequently the reaction intermediate is a surface site at which the lattice atoms are partially bonded to one another and partially to hydrogen and fluorine.

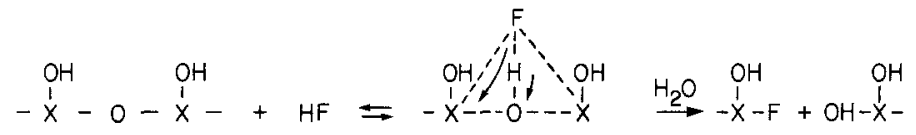

where $\mathrm{X}$ represents silicon, aluminum, or magnesium. It is important to note that the dissolution of silicates by HF cannot be attributed solely to either protonation of the lattice bonds or the nucleophilic fluoride attack since the rates of dissolution in comparable concentrations of $\mathrm{HCl}$ or $\mathrm{NH}_{4} \mathrm{~F}$ are negligibly slow. Rather, it can be concluded that both steps must take place simultaneously.

This reaction mechanism does not require that the lattice bonds be protonated by the specific protons associated with the HF molecule. A similar intermediate characterizes the catalyzed reaction when $\mathrm{HF}$ molecules and $\mathrm{H}^{+}$ions are both adsorbed at the surface.

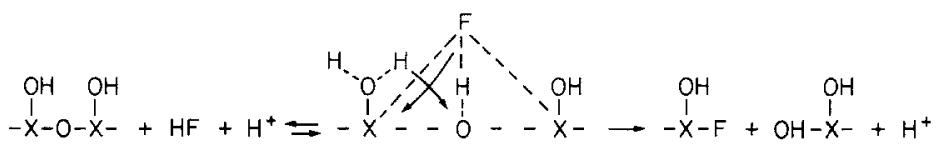

The only difference between these two reactions is the manner in which the lattice bonds are protonated. In the uncatalyzed reaction, the only protons available are associated with the HF molecule. In the parallel catalyzed reaction, the lattice bonds are protonated by hydrogen ions adsorbed at the surface. The corresponding intermediates are not identical, and the preexponential terms of the rate constants $k_{0}$ and $k_{1}$ can differ considerably. They are apparently similar enough, however, that the activation energies are the same.

The experimentally determined values of the $\mathrm{H}^{+}$adsorption constant $K_{2}$ are also presented in Table II, along with heats of adsorption calculated by the van't Hoff equation:

$$
\frac{d\left(\ln K_{2}\right)}{d T}=\frac{\Delta H}{R T^{2}} .
$$

It can be seen that the adsorption of $\mathrm{H}^{+}$ varies considerably from mineral to mineral. One notes, however, that the adsorption constant $K_{2}$ is apparently not a function of the catalysis parameter $k_{1} / k_{0}$. For instance, the equilibrium adsorption constants characterizing quartz and feldspar are very similar, while the respective catalysis parameters differ by a factor of nine.

The calculated heat of adsorption for montmorillonite is substantially greater than the values of $\Delta H$ determined for kaolinite, potassium feldspar, and quartz. Consequently the magnitudes of the montmorillonite $\mathrm{H}^{+}$adsorption constant $K_{2}$ can be quite large. At $25^{\circ} \mathrm{C}$, the value of $K_{2}$ for sodium montmorillonite is 8.0 , compared to 0.39 for kaolinite and $\mathbf{0 . 0 5 6}$ for quartz.

An analogous trend characterizes the HF 
adsorption constant $K_{\mathrm{A}}$. In a previous study (2) of the uncatalyzed dissolution of seven different silicates it was shown that the denominator of the Langmuir-Hinshelwood rate law,

$$
-r_{0}=\frac{k_{0} K_{\mathrm{A}}\left(a_{\mathrm{HF}}\right)}{1+K_{\mathrm{A}}\left(a_{\mathrm{HF}}\right)},
$$

is significantly different from unity only for sodium montmorillonite. Over a temperature range of 0 to $70^{\circ} \mathrm{C}$, the uncatalyzed dissolution of the other silicates studied followed first-order kinetics,

$$
-r_{0}=k_{0} K_{\mathrm{A}}\left(a_{\mathrm{HF}}\right),
$$

indicating that the magnitudes of the adsorption constants $K_{\mathrm{A}}$ for these minerals are small compared to montmorillonite. The strong adsorption of the HF molecules at the montmorillonite surface was related to the large ion-exchange capacity, and was attributed to the specific adsorption of the polar HF molecules at the negative exchange sites. In an analogous manner, the strong adsorption of hydrogen ions at the montmorillonite surface can also be attributed to the large ion-exchange capacity. Hydrogen ions are chemically adsorbed at the exchange sites, as is evident from the wellknown fact that hydrogen montmorillonites spontaneously decompose, liberating aluminum from the lattice. The mechanism of this decomposition - weakening of the lattice bonds by protonation, followed by hydrolysis-is similar to the $\mathrm{H}^{+}$catalysis of $\mathrm{HF}$ attack.

\section{SUMMARY}

The results of this study show that the dissolution of silicate minerals by hydrofluoric acid is a catalyzed system in which the rate of attack by molecular HF is increased by the additional presence of strong acids in the reacting mixture. A model was developed that successfully describes the kinetics of the catalyzed dissolution of kaolinite, quartz, potassium feldspar, and sodium montmorillonite. The overall dissolution consists of two parallel surface reactions - uncatalyzed attack by adsorbed HF molecules and a reaction catalyzed by the presence of adsorbed protons. The fraction by which the rate of dissolution is increased is given by a parameter called the degree of acid catalysis, $D_{\mathrm{AC}}$,

$$
D_{\mathrm{AC}}=\frac{k_{1}}{k_{0}} \frac{K a_{\mathrm{H}}}{1+K a_{\mathrm{H}}},
$$

where $k_{0}$ and $k_{1}$ are the specific rate constants of the uncatalyzed and catalyzed reactions, respectively, $K$ is the equilibrium adsorption constant for the adsorption of $\mathrm{H}^{+}$ at the silicate surface, and $a_{\mathrm{H}}$ is the bulk hydrogen ion activity. The ratio $k_{1} / k_{0}$, termed the catalysis parameter, $P_{\mathrm{C}}$, represents the maximum fraction by which the dissolution of any given silicate can be catalyzed. This maximum is a strong function of the nature of the mineral surface, a fact that has utility in the area of designing for selective dissolution in composite systems.

\section{REFERENCES}

1. Hekim, Y., and Fogler, H. S., Chem. Eng. Sci. 32, 1 (1977).

2. Kline, W. E., Ph.D. thesis, University of Michigan (1980).

3. Fogler, H. S., Lund, K., and McCune, C. C., Chem. Eng. Sci. 30, 1325 (1975).

4. Harriott, P., AIChE J. 8, 93 (1962).

5. Friedlander, S. K., AIChE J. 3, 43 (1957).

6. Harned, H. S., and Owen, B. B., "The Physical Chemistry of Electrolyte Solutions," 3rd ed. Reinhold, New York, 1958.

7. Mer, R. K., "The Chemistry of Silica." Wiley, New York, 1979.

8. Dean, J. A., (Ed.), "Lange's Handbook of Chemistry," 11th ed. McGraw-Hill, New York, 1973.

9. Strelko, V. V., Teor. Eksp. Khim. 10, 359 (1973). 